NASA/TM-2000-209778

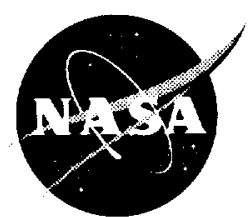

\title{
Design and Operating Characteristics of High-Speed, Small-Bore Cylindrical-Roller Bearings
}

Stanley I. Pinel

Pinel Engineering, Fullerton, California

Hans R. Signer

Signer Technical Services, Fullerton, California

Erwin V. Zaretsky

Glenn Research Center, Cleveland, Ohio

Prepared for the

2000 Annual Meeting

sponsored by the Society of Tribologists and Lubrication Engineers

Nashville, Tennessee, May 7-11, 2000

National Aeronautics and

Space Administration

Glenn Research Center 


\section{Acknowledgments}

We would like to thank John Salverda and acknowledge his contribution to this paper. Mr. Salverda reprogrammed the SHABERTH computer code significantly improving its performance. He performed the parametric analysis of the 35-mm-bore cylindrical roller bearing with the improved code.

Available from

NASA Center for Aerospace Information

7121 Standard Drive

Hanover, MD 21076

Price Code: A03
National Technical Information Service 5285 Port Royal Road Springfield, VA 22100 Price Code: $\mathrm{A03}$

Available electronically at http://gltrs.grc.nasa.gov/GLTRS 


\title{
Design and Operating Characteristics of High-Speed, Small-Bore Cylindrical-Roller Bearings
}

\author{
Stanley I. Pinel \\ Pinel Engineering \\ Fullerton, California \\ Hans R. Signer \\ Signer Technical Services \\ Fullerton. California \\ Erwin V. Zaretsky \\ National Aeronautics and Space Administration \\ Glenn Research Center \\ Cleveland, Ohio
}

The computer program SHABERTH was used to analyze 35-mm-bore cylindrical roller bearings designed and manufactured for high-speed turbomachinery applications. Parametric tests of the bearings were conducted on a highspeed, high-tempcrature bearing tester and the results were compared with the computer predictions. Bearings with a channeled inner ring were lubricated through the inner ring, while bearings with a channeled outer ring were lubricated with oil jets. Tests were run with and without outer-ring cooling. The predicted bearing life decreased with increasing speed because of increased contact stresses caused by centrifugal load. Low'er temperatures, less roller skidding and lower power losses were obtained with channeled inner rings. Power losses calculated by the SHABERTH computer program correlated reasonably well with the test results. The Parker formula for XCAV (used in SHABERTH as a measure of oil volume in the bearing cavity) needed to be adjusted to reflect the prevailing operating conditions. The XCAV formula will need to be further refined to reflect roller bearing lubrication. ring design. cage design. and location of the cagecontrolling land.

\section{INTRODUCTION}

Aircraft turbine engines in the small class $(0.45$ to $4.5 \mathrm{~kg} / \mathrm{sec}$ or 1 to $10 \mathrm{lb} / \mathrm{sec}$ total airflow) require rolling-element bearings to operate at temperatures to $218^{\circ} \mathrm{C}\left(425^{\circ} \mathrm{F}\right)$ and at speeds in excess of 2.5 million DN. (DN is defined as the speed of the shaft in revolutions/minute multiplied by the bearing bore in millimeters.) To achieve speeds of $3 \mathrm{million}$ DN with angular-contact ball bearings and cylindrical roller bearings, Zaretsky et al. (1) and Signer et al. (2) proposed the concept of bearing thermal management as the proper technological approach to high-speed bearing operation. Under-ringlubricated bearings were provided with outer-ring cooling. The basis of this concept was the recognition that total and flexible thermal control over all the bearing components was essential to achieving a reliable high-speed, highly loaded bearing. Research reported by Zaretsky et al. (1), Signer et al. (2), and Bamberger et al. (3.4) showed that bearings could be operated reliably for long periods at speeds to 3 million DN with lubrication through annular passages extending radially through the bearing split inner ring and lands (under-race lubrication) and with outer-ring cooling.

Parametric tests on 35-mm-bore angular-contact and split inner-ring ball bearings were performed by us and reported in refs. (5-11). For the ball bearings having a split inner ring and under-ring lubrication, optimal operating conditions were obtained with an inner-ring, land-guided cage, using outer-ring cooling in conjunction with low lubricant flow rates. Lower temperatures and power losses were obtained with a single outer-ring, land guided cage having a relieved inner ring and partially relieved outer ring. Reasonably good engineering correlation was obtained using the computer program $S H A B E R T H$ for predicted power loss and for inner- and outer-ring temperatures. The Parker formula (12) for XCAV (used in $S H A B E R T H$, a measure of the oil flow volume in the bearing cavity) was found to need refinement to better reflect bearing lubrication mode, cage design, and location of the cage controlling land.

Applying under-ring lubrication to small-bore cylindrical roller bearings is more difficult than applying it to larger bore sizes. Limited space is available for grooves and radial holes for supplying the lubricant under the inner ring. For a given DN value, centrifugal effects are more severe with small bearings because centrifugal force varies with the square of the speed where DN is proportional to speed. Heat generated per unit of surface area is much higher and heat removal is more difficult. 
The objective of the research reported herein was to extend our work (5-11) to include the effect of bearing and cage design, shaft speed, lubricant flow rate, and outer-ring cooling on the operation of 35 -mm-bore cylindrical roller bearings.

\section{APPARATUS, SPECIMENS, AND PROCEDURE}

\section{High-Speed Bearing Tester}

A schematic drawing of the air turbine-driven test machine initially described by Pinel and Signer (13) is shown in Fig. 1. The horizontally mounted shaft was assembled with a set of preloaded angular contact ball bearings on the turbine end and a cylindrical roller bearing on the test bearing end. The test bearing was overhung and mounted in a separate housing that incorporated the hardware for lubrication, oil removal, radial load application, and instrumentation for cage speed measurement. For these tests, the test bearing was a cylindrical roller bearing. The test bearing was radially loaded through a hydraulically powered yoke. The test bearing torque was measured with strain gauges located near the end of an arm that prevented the housing from rotating.

The test bearing can either be lubricated through the bearing inner ring and/or by a pair of stationary lubricant jets. The jet outlets were located $\sim 3 \mathrm{~mm}(0.12 \mathrm{in}$.) from the face of the bearing. In separate tests with ball bearings, not reported herein. it was determined that a $20 \mathrm{~m} / \mathrm{sec}(66 \mathrm{ft} / \mathrm{sec})$ jet velocity provided the most efficient test bearing lubrication; therefore, this velocity was used in all the tests reported. (Miyakawa et al. (14) reported a similar efficiency with a $20 \mathrm{~m} / \mathrm{sec}(66 \mathrm{ft} / \mathrm{sec})$ jet velocity over other velocities.)

For inner-ring lubrication, oil was pumped by centrifugal force from the center of the hollow shaft through axial grooves in the test bearing bore and through a series of small radial holes, $0.762 \mathrm{~mm}(0.030 \mathrm{in}$.) in diameter, to the bearing inner race. The axial grooves in the bearing bore provided cooling for the inner ring.

Cooling of the test bearing outer ring is accomplished by supplying oil to the annular grooves in the bearing mounting surfaces as shown in Fig. 1. Oil flow could be varied with the objective of equalizing the inner- and outer-ring temperatures.

\section{Test Bearings}

Two cylindrical roller bearing configurations shown in Fig. 2 designed and manufactured for high-speed turbomachinery applications were investigated. These were a channeled inner-ring bearing that used an inner-ring-guided cage (Fig. 2(a)) and a channeled outer-ring roller bearing that used an outer-land guided cage (Fig. 2(b)). The specifications for both test bearings are summarized in Table 1. The bearings were an ABEC 7 grade and each contained 16 rollers with a nominal 7.14-mm (0.281-in.) diameter and length. The inner and outer rings and the rollers were manufactured from consumableelectrode, vacuum-melted, AISI M-50 steel. The surface finishes of the races were $0.125 \mu \mathrm{m}(4.9 \mu$ in.) Arithmetic Average (AA) or better. The surface finish of the rollers was $0.075 \mu \mathrm{m}(2.4 \mu \mathrm{in}$.). The bearing surface composite finish was $0.13 \mu \mathrm{m}(5.0 \mu \mathrm{in}$.). The nominal hardness of the rollers and rings was Rockwell $\mathrm{C} 62$ at room temperature.

The cage was manufactured from AISI 4340 steel (AMS 6415) heat treated to Rockwell C 28 to 34 hardness. It was completely coated with a $0.02-$ to $0.04-\mathrm{mm}(0.0008-$ to 0.0015 -in.) thickness of silver plate (AMS 2412). The cage balance was within $0.05 \mathrm{~g}-\mathrm{cm}\left(7 \times 10^{-3} \mathrm{oz}-\mathrm{in}.\right)$.

\section{Test Procedure}

After the test machine had been warmed by recirculating heated oil and the torque-measuring system had been calibrated, a $667 \mathrm{~N}$ (150 lbf) radial load and a $1.9 \mathrm{f} / \mathrm{min}(0.50 \mathrm{gal} / \mathrm{min})$ lubricant flow rate were applied. The shaft speed was then slowly brought up to a nominal $28,000 \mathrm{rpm}$. When the bearing and test machine temperatures stabilized (after 20 to $25 \mathrm{~min}$ ), the oil-inlet temperature and lubricant flow rate were set and the speed was increased to the desired value.

A test series was run by starting at the lowest nominal speed, 50,000 rpm, progressing through 65,000 and $72,000 \mathrm{rpm}$ before changing the lubricant flow rate. At each speed and flow condition, a separate test was run during which the outer-ring cooling oil flow was adjusted to achieve equal inner- and outer-ring temperatures. Four lubricant flow rates ranging from 0.3 to $1.9 \mathrm{f} / \mathrm{min}(0.08$ to $0.50 \mathrm{gal} / \mathrm{min})$ were used.

The first series of tests on the channeled inner-ring bearings were run with $667 \mathrm{~N}$ (150 lbf) radial load. The remaining tests were run with $1334 \mathrm{~N}$ (300 lbf) radial load. During testing, if it became apparent that the conditions would result in 
predictable distress of the test bearing or test rig or that the bearing temperature would exceed $218^{\circ} \mathrm{C}\left(425^{\circ} \mathrm{F}\right)$, the test was aborted.

The shaft speed (inner-ring speed) was measured with a magnetic probe. The ball-pass frequency (cage speed) was measured with a semiconductor strain gauge mounted in a cavity of the housing and was displayed on a spectrum analyzer.

Two thermocouples were assembled in the shaft so that the centrifugal force would push them against the test bearing inner ring. Temperature readings were transmitted with a rotating telemetry system mounted on an auxiliary shaft at the air turbine end of the test machine. Outer-ring temperatures were obtained by two thermocouples installed in the test-bearing housing, one located $45^{\circ}$ from the center of the radial load zone of the bearing and the other positioned $180^{\circ}$ from the first. For accurate measurement of oil-in and oil-out temperatures, thermocouples were placed directly in the housing fittings of the lubricating jets and in the oil discharge reservoir, as shown in Fig. 1.

The channeled inner-ring bearing design permitted lubrication through the inner ring by means of axial grooves machined in the bore. Radial holes, $0.762-\mathrm{mm}(0.030$-in.) in diameter, radiating from the bearing bore formed a flow path for bearing lubrication. The bearing inner-ring grooves and radial holes were designed so that 100 percent of the oil supplied to the inner ring lubricated the bearing. This flow also cooled the inner ring. Bearings with a channeled inner ring were lubricated through the inner ring, while bearings with a channeled outer ring were lubricated with oil jets.

\section{Lubricant}

The lubricant used for the parametric studies was neopentylpolyol (tetra) ester. This Type II oil is qualified to the MILL-23699 specifications and also to the internal oil specifications of most major aircraft engine manufacturers. The major properties of the lubricant are presented in Table 2.

\section{RESULTS AND DISCUSSION}

\section{Life Analysis}

The computer program SHABERTH (15) was used to calculate the contact (Hertz) stresses and life of the test bearings. The results of this analysis are summarized in Table 3. All computations were made with temperatures resulting from a lubricant flow rate of $0.76 \mathrm{f} / \mathrm{min}(0.20 \mathrm{gal} / \mathrm{min})$ with no outer-ring cooling. The measured inner- and outer-ring temperatures were used for these calculations. The effect of speed on the maximum Hertz stress for the inner and outer races is shown in Fig. 3 and summarized in Table 3.

For both the $667 \mathrm{~N}$ (150 lbf) and $1334 \mathrm{~N}$ (300 lbf) radial loads, the outer-race stresses increase with speed. whereas the inner-race stresses remain relatively unchanged. The outer-race stress, because of centrifugal effects, exceeds that of the inner race. The bearing becomes outer-race life dependent, that is, with speed, the components having the highest probability of failure shifts from the inner race to the outer race.

Figure 4 shows the resultant calculations for bearing $L_{10}$ life as a function of speed. The $L_{10}$ life is the time in hours that 90 percent of a population of bearings would be expected to exceed without failing or that time within which 10 percent of the population will have failed. Life factors from (16) (Table 1) were incorporated in the SHABERTH computer analysis. The bearings available for testing had a composite surface finish of $0.13 \mu \mathrm{m}(5.1 \mu \mathrm{in}$.) AA. Composite surface finishes of $0.05 \mu \mathrm{m}(2 \mu \mathrm{in}$.) AA are commonly found in better commercial quality bearings. Both levels of surface finish were analyzed. (The composite surface finish is $\sigma=\left(\sigma_{\text {roll }}^{2}+\sigma_{r}^{2}\right)^{1 / 2}$ where $\sigma_{\text {roll }}$ and $\sigma_{r}$ are the Arithmetic Average (AA) surface finishes of the rollers and races, respectively.) Also, it was assumed that the AISI M-50 steel processing was both CEVM (VAR), single-vacuum-melted, and VIM-VAR, double-vacuum-melted (Table 1 and Zaretsky (16)). These assumptions resulted in changes of life factors $a_{2}$ for material and processing and $a_{3}$ for lubrication (16). The $a_{2}$ and $a_{3}$ life factors are summarized in Tables 1 and 3 , respectively.

With reference to Fig. 4(a), life in hours decreases with speed and radial load. Improved surface finish significantly improves bearing life as shown in Fig. 4(b). Combining this improvement in surface finish with the double-vacuum-melted (VIM-VAR) material, processing of the AISI M-50 steel can further double the expected bearing life. Even with this life improvement, the absolute life in hours may not be sufficient for many commercial aircraft engine applications compared with what can be obtained for lower-speed applications. This would imply that there is a need to further optimize bearing design for higher-speed applications to obtain longer bearing life. For example, a change in the roller crown profile to a partial crown and extending the crown radius to $460 \mathrm{~mm}$ ( $18 \mathrm{in}$.) would further increase bearing life as indicated in Table 3 and Fig. 4(c). 


\section{Bearing Power Loss}

While originally developed for ball bearings, the XCAV factor may be applied successfully to cylindrical roller bearings. Since values for XCAV are a function of bearing geometry, different bearing configurations will require different XCAV values.

The bearing cavity is defined as the space between the inner and outer races that is not occupied by the cage and the balls or rollers. The authors of Ref. (15) recommend that the values used for XCAV be less than 5 percent. It is expected that XCAV vary with lubricant flow rate, shaft speed, and bearing size. Previous work $(17,18)$ has shown that XCAV values of two-to-three percent generally correlate well with the experimental data over a small range of conditions. Lubricant flow rate and shaft speed were not correlated with XCAV in these previous works.

Parker (12) derived an equation for XCAV based on a comparison of the heat generation, temperature, and lubricant flow rate for three sizes of angular-contact ball bearings. The Parker equation for XCAV follows for SI units:

$$
\mathrm{XCAV}=10.0 \times 10^{6} \frac{\mathrm{W}^{0.37}}{N \mathrm{~d}_{\mathrm{m}}^{1.7}}
$$

where the variables are lubricant flow rate $W . \mathrm{cm}^{3} / \mathrm{min}$; inner-race speed $N$, rpm; and pitch diameter $d_{\mathrm{m}}$. mm. The equation in English units is

$$
\mathrm{XCAV}=8.62 \times 10^{5} \frac{\mathrm{W}^{0.37}}{N \mathrm{~d}_{\mathrm{m}}^{1.7}}
$$

where $W$ is in $\mathrm{gal} / \mathrm{min}, N$ is in $\mathrm{rpm}$, and $d_{m}$ is in inches.

To assess the effects of shaft speed and lubricant flow on XCAV, the SHABERTH computer program was used to calculate the performance of the $35-\mathrm{mm}$ bore. cylindrical roller bearing for speeds from 50,000 to $72.200 \mathrm{rpm}$ and lubricant flow rates from 0.30 to $1.9 \mathrm{l} / \mathrm{m}(0.08$ to $0.50 \mathrm{gal} / \mathrm{min})$. The radial load and oil-in temperatures were held constant at $667 \mathrm{~N}$ $(150 \mathrm{lbf})$ or $1334 \mathrm{~N}(300 \mathrm{lbf})$ and $121^{\circ} \mathrm{C}\left(250^{\circ} \mathrm{F}\right)$, respectively. The results of this analysis are shown in Fig. 5 . Bearing power loss increases linearly with lubricant volume percent and also increases with bearing speed. This analysis would suggest that, to minimize loss at a higher speed. lubricant flow to the bearing be minimized while the temperature be maintained at acceptable levels, i.e.. $<218{ }^{\circ} \mathrm{C}\left(<425{ }^{\circ} \mathrm{F}\right)$. The bearing (oil) temperature affects the elastohydrodynamic film thickness, which does have an effect on bearing life. Hence, the engineer must carefully balance acceptable bearing power loss and bearing life and reliability requirements. Some of the factors that influence the lubricant fill in the bearing are oil flow rate, viscosity, density. housing and shaft configuration, cage design, and bearing ring-land configuration.

\section{Lubricant Flow Rate}

The measured temperatures are shown in Fig. 6 for the bearing with the channeled inner ring at $667 \mathrm{~N}(150 \mathrm{lbf})$ and $1334 \mathrm{~N}$ (300 lbf). The inner- and outer-ring temperatures decreased and power consumption increased as lubricant flow rate increased. These results are consistent with reported temperature measurements made with high-speed ball bearings.

The difference in temperature $(\Delta T)$ between the inner and outer races was mildly affected by the lubricant flow rate. At $50.000 \mathrm{rpm}$ with the lower flow rate of $0.76 \mathrm{f} / \mathrm{min}(0.20 \mathrm{gal} / \mathrm{min}) \Delta T$ between the outer and inner rings was $\sim 22{ }^{\circ} \mathrm{C}\left(40{ }^{\circ} \mathrm{F}\right)$. At $72,000 \mathrm{rpm} \Delta T$ was $-35^{\circ} \mathrm{C}\left(63^{\circ} \mathrm{F}\right)$ with a maximum outer-ring temperature of $210^{\circ} \mathrm{C}\left(410^{\circ} \mathrm{F}\right)$. As the lubricant flow rate increased to $1.9 \mathrm{\ell} / \mathrm{min}(0.50 \mathrm{gal} / \mathrm{min})$, the $\Delta T$ was reduced to 10 and $22^{\circ} \mathrm{C}\left(18^{\circ}\right.$ and $\left.22{ }^{\circ} \mathrm{F}\right)$ at 50,000 and $72,000 \mathrm{rpm}$, respectively. At $72,000 \mathrm{rpm}$, the maximum outer-race temperature was $-178{ }^{\circ} \mathrm{C}\left(352{ }^{\circ} \mathrm{F}\right)$. The results are consistent with past experience which has shown that with increased lubricant flow rate race temperatures will decrease and then begin to increase at some intermediate flow rate.

So that heat rejection (power loss) could be thermally determined, oil-inlet and oil-outlet temperatures were measured for all flow conditions. The heat absorbed by the lubricant was obtained from the standard heat-transfer equation: 


$$
Q_{T}=m C_{p}\left(t_{\text {out }}-t_{\text {in }}\right)
$$

Where $Q_{T}=$ total heat-transfer rate to lubricant, $\mathrm{J} / \mathrm{min}(\mathrm{Btu} / \mathrm{min}) ; m=$ mass flow rate, $\mathrm{kg} / \mathrm{min}(\mathrm{lbm} / \mathrm{min})$ : $C_{r}=$ specific heat, $\mathrm{J} / \mathrm{kg}{ }^{\circ} \mathrm{K}\left(\mathrm{Btu} / \mathrm{lbm}{ }^{\circ} \mathrm{F}\right) ; t_{\text {out }}=$ oil-outlet temperature, ${ }^{\circ} \mathrm{C}\left({ }^{\circ} \mathrm{F}\right) ; t_{\mathrm{in}}=$ oil-inlet temperature, ${ }^{\circ} \mathrm{C}\left({ }^{\circ} \mathrm{F}\right)$.

Figure 7(a) shows the effect of lubricant flow rate on bearing power loss. The power loss shown was measured mechanically and thermally. The thermal measurements were consistently $0.2 \mathrm{~kW}(0.3 \mathrm{hp})$ higher than those determined mechanically. This difference can be attributed to (a) oil churning losses measured by the thermal method and not captured by the mechanical method and (b) inaccuracies in the lubricant specific heat values that were available.

The power loss increased linearly with flow rate. At a lubricant flow rate of $0.76 \mathrm{\ell} / \mathrm{min}(0.20 \mathrm{gal} / \mathrm{min})$, the power loss was $\sim 0.93 \mathrm{~kW}(1.25 \mathrm{hp})$ at $50,000 \mathrm{rpm}$ and $1.7 \mathrm{~kW}(2.25 \mathrm{hp})$ at $72.000 \mathrm{rpm}$. At the flow rate of $1.9 \mathrm{C} / \mathrm{min}$ $(0.50 \mathrm{gal} / \mathrm{min})$, the power loss was $1.4 \mathrm{~kW}(1.9 \mathrm{hp})$ at $50.000 \mathrm{rpm}$ and $3.0 \mathrm{~kW}(4.0 \mathrm{hp})$ at $72,000 \mathrm{rpm}$.

The predicted power loss (Fig. 7(b)) showed the same trend as the experimental data but was higher than that measured mechanically or thermally. The differences between the measured and predicted losses were reasonably consistent. At $50,000 \mathrm{rpm}$, the difference between the power loss measured thermally and that calculated ranged from 0.4 to $0.8 \mathrm{~kW}(0.5$ to $1.1 \mathrm{hp})$. At $70,000 \mathrm{rpm}$, this difference was $\sim 0.8 \mathrm{~kW}(1.1 \mathrm{hp})$.

\section{Effect of Speed}

The effects of speed on bearing temperature, power loss and cage speed ratio were studied for cylindrical roller bearings with raceway channels on inner rings or outer rings (Fig. 2). Radial loads of $667 \mathrm{~N}(150 \mathrm{lbf}$ ) and $1334 \mathrm{~N}$ (300 lbf) were applied. Speed was varied from 50,000 to $72,000 \mathrm{rpm}$. The oil-inlet temperature was held constant at $121^{\circ} \mathrm{C}\left(250^{\circ} \mathrm{F}\right)$.

Figures 8 (a) to (e) show bearing ring temperatures as a function of speed for loads of $667 \mathrm{~N}(150 \mathrm{lbf})$ and $1334 \mathrm{~N}$ ( $300 \mathrm{lbf}$ ), with and without outer-ring cooling for both the channeled inner-ring and channeled outer-ring bearings.

Generally, ring temperatures increased with increasing speeds and decreasing lubricant flows. The ring temperatures of the roller bearings with a channeled inner ring was $\sim 135^{\circ} \mathrm{C}\left(275^{\circ} \mathrm{F}\right)$ for both rings at the lowest speeds and highest flows. The highest temperatures for the inner ring was $170^{\circ} \mathrm{C}\left(338^{\circ} \mathrm{F}\right)$ and $200^{\circ} \mathrm{C}\left(392^{\circ} \mathrm{F}\right)$ for the outer ring at the highest speed with $0.76 \mathrm{f} / \mathrm{min}(0.20 \mathrm{gpm})$ flow, which is the lowest allowed flow. On the average, bearing ring temperatures were affected by less than $5^{\circ} \mathrm{C}\left(9^{\circ} \mathrm{F}\right)$ when increasing the radial load from $667 \mathrm{~N}(150 \mathrm{lbf})$ to $1334 \mathrm{~N}(300 \mathrm{lbf})$.

Tests with lower lubricant flow rates were not run at speeds above $50.000 \mathrm{rpm}$ as ring temperatures would have exceeded the set limit of $218^{\circ} \mathrm{C}\left(425^{\circ} \mathrm{F}\right)$. The difference between the outer- and inner-ring temperatures $\Delta T$ varied from 0 to $28{ }^{\circ} \mathrm{C}\left(0\right.$ to $\left.50^{\circ} \mathrm{F}\right)$.

To improve bearing life and to maintain a small internal diametrical clearance (IDC), it may be desirable to thermally manage the bearing. A way to control IDC is by cooling the bearing outer raceway. This method was extensively reported in refs. (1-4). Figure 8 shows the effect of bearing outer-ring cooling on inner- and outer-ring temperatures. In these tests. the outer-ring cooling was used to match the inner- and outer-ring temperatures.

Figures 9 (a) to (e) show the effect of speed on power loss for the bearing with a channeled inner and outer ring, $667 \mathrm{~N}$ (150 lbf) and $1334 \mathrm{~N}(300 \mathrm{lbf}$ ) radial load, and with and without outer-ring cooling. As would be expected, power loss increases with speed and load. At $667 \mathrm{~N}(150 \mathrm{lbf})$, the power loss ranged from $\sim 0.5 \mathrm{~kW}(0.7 \mathrm{hp})$ at $50,000 \mathrm{rpm}$ to $\sim 2.5 \mathrm{~kW}$ $(3.4 \mathrm{hp})$ at $72,000 \mathrm{rpm}$. Outer-ring cooling had only a nominal effect on bearing power loss. Increasing load on the bearing to $1334 \mathrm{~N}$ ( $300 \mathrm{lbf})$ increased the power loss by less than $0.4 \mathrm{~kW}(0.5 \mathrm{hp})$.

In Fig. 9, the experimental results were compared with the SHABERTH computer program predictions for power loss as a function of speed. The experimental results compared favorably to predictions generated by the computer program.

Optimal operating conditions for this bearing at high speed can be achieved by using outer-ring cooling in conjunction with low lubricant flow rates. Since the ring temperatures with outer-ring cooling are cooler, less oil flow is needed to lubricate and internally cool the bearing. Less oil flow inside the bearing cavity means less bearing power loss.

In general, the tests with the channeled outer-ring bearings follow the same trends as the channeled inner-ring bearings. Differences in measurements are attributed to pooling of the oil in the raceway channel as the roller compliment has to plow through the pool of oil. This requires higher power resulting in higher operating temperatures. 


\section{Cage Slip}

The difference between the cage epicyclic speed ratio ( 0.427 for these bearings) and the measured cage speed ratio is indicative of roller slip. There is little difference in the cage speed ratios in tests with and without outer ring cooling as can be seen in Figs. 10(a) to (d). However, changing the radial load can affect the cage speed ratio significantly. Examination of the channeled inner-ring bearing indicates increasing slippage with increasing shaft speed at $667 \mathrm{~N}$ ( $150 \mathrm{lbf}$ ) radial load. In contrast, at $1334 \mathrm{~N}(300 \mathrm{lbf}$ ) radial load, the cage speed ratio is close to the epicyclic speed ratio and varies only slightly with speed.

Cage slippage in the channeled outer-ring bearing is greater at all conditions. This effect may be attributed to the pooling of oil in the outer raceway channel. At $1334 \mathrm{~N}(300 \mathrm{lbf}$ ) radial load, as the shaft speed is increased. the cage speed ratio greatly decreases. This is shown in Fig. 10(e).

\section{SUMMARY OF RESULTS}

The computer program SHABERTH was used to analyze 35 -mm-bore cylindrical roller bearings designed and manufactured for high-speed turbomachinery applications. Parametric tests of the bearings were conducted in a high-speed, high-temperature bearing tester. The results were compared with the computer predictions. Two bearing designs were studied. one with a channeled inner ring and the other with a channeled outer ring. The test conditions were shaft speeds from 50.000 to $72,000 \mathrm{rpm}$ ( 1.75 to 2.5 million DN) and an oil-inlet temperature of $121^{\circ} \mathrm{C}\left(250{ }^{\circ} \mathrm{F}\right)$. Bearings with a channeled inner ring were lubricated through the inner ring, while bearings with a channeled outer ring were lubricated with oil jets. Some tests were run with and without outer-ring cooling. The lubricant was a neopentylpolyol (tetra) ester that met the MIL-L-23699 specification. The following results were obtained.

1. At all conditions tested, the bearing design with a channeled inner raceway and inner-land guided cage ran cooler and with lower power demand than the bearing with its raceway channel in the outer ring.

2. Increasing external radial load to the test bearing from $667 \mathrm{~N}(150 \mathrm{lbf})$ to $1334 \mathrm{~N}(300 \mathrm{lbf})$ had no significant effect on bearing ring temperatures or power demand. Generally, power demand increased with increasing shaft speeds and with increasing lubricant supply to the bearing. Within the envelope of tested conditions, ring temperatures decreased with increasing lubrication flow rates.

3. Applying cooling oil flow to the bearing outer ring outside diameter reduced outer-ring temperatures without affecting inner-ring temperatures significantly. With this technique, bearing inner and outer rings could be thermally balanced. As a result, less oil flow is needed in the bearing cavity, and the bearing power loss is reduced.

4. There is little difference in the cage speed ratios in tests with and without outer-ring cooling. However, with the channeled inner-ring bearing, changing the radial load can affect the cage speed ratio significantly. With the lower radial load. the cage slip increased with increasing shaft speed. In contrast, at the higher radial load, the cage speed ratio is close to the epicyclic speed ratio and varied only slightly over the full speed range. The cage slip of the channeled outer-ring bearings is larger than for the channeled inner-ring bearings at lower speeds and increases rapidly with increasing speed.

5. Reasonably good engineering correlation was obtained using the computer program SHABERTH for predicted bearing power loss in comparison with measured values. As with ball bearings, the Parker formula for XCAV (in SHABERTH. a measure of oil volume in the bearing cavity) needed to be adjusted to reflect roller bearing lubrication, ring design, cage design. and location of the cage-controlling land.

\section{REFERENCES}

(1) Zaretsky. E.V.. Bamberger, E.N. and Signer, H., "Operating Characteristics of 120-Millimeter-Bore Ball Bearings at $3 \times 10^{\circ}$ DN," NASA TN D-7838, (1974).

(2) Signer, H., Bamberger. E.N. and Zaretsky, E.V., "Parametric Study of the Lubrication of Thrust Loaded 120-mmBore Ball Bearings to 3 Million DN,"Jour. Lubr. Tech., Trans. ASME, 96, 3, pp. 515-525. (1974).

(3) Bamberger, E.N.. Zaretsky, E.V. and Signer, H., "Effect of Speed and Load on Ultra-High Speed Ball Bearings," NASA TN D-7870, (1975).

(4) Bamberger, E.N., Zaretsky, E.V. and Signer, H., "Endurance and Failure Characteristic of Main-Shaft Jet Engine Bearing at $3 \times 10^{\circ}$ DN,"Jour. Lubr. Tech., Trans. ASME, 98, 4, pp. 580-585, (1976). 
(5) Schuller, F.T., Pinel, S.I. and Signer, H.R., "Operating Characteristics of High-Speed-Jet-Lubricated 35-MillimeterBore Ball Bearings With a Single-Outer-Land-Guided Cage," NASA TP-1657, (1980).

(6) Schuller, F.T., Pinel. S.I. and Signer. H.R., "Effect of Cage Design on Characteristics of High-Speed-Jet-Lubricated 35-Millimeter-Bore Ball Bearings," NASA TP-1732, (1980).

(7) Schuller, F.T. and Signer, H.R., "Performance of Jet- and Inner-Ring-Lubricated 35-Millimeter-Bore Ball Bearings Operating to 2.5 Million DN," NASA TP-1808. (1991).

(8) Signer. H.R. and Schuller, F.T., "Lubrication of 35-Millimeter-Bore Ball Bearings of Several Designs at Speeds to 2.5 Million DN," Problems in Bearings and Lubrication, AGARD CP-320, (1983).

(9) Schuller, F.T., "Lubrication of 35-Millimeter-Bore Ball Bearings of Several Designs at Speeds to 2.5 Million DN." Advanced Power Trans. Tech., Fischer, G.K.. ed., NASA CP-2210, pp. 221-237, (1983).

(10) Schuller, F.T., Pinel, S.I. and Signer, H.R., "Effect of Two Inner-Ring Oil-Flow Distribution Schemes on the Operating Characteristics of a 35-Millimeter-Bore Ball Bearing to 2.5 Million DN." NASA TP-2404, (1985).

(11) Pinel, S.I., Signer, H.R. and Zaretsky, E.V.: "Design and Operating Characteristics of High-Speed, Small-Bore, Ball Bearings," Tribology Trans., 41. 4, pp. 423-434. (1998).

(12) Parker. R.J., "Comparison of Predicted and Experimental Thermal Performance of Angular-Contact Ball Bearings," NASA TP-2275. (1984).

(13) Pinel, S.I. and Signer, H.R., "Development of a High-Speed. Small Bore Bearing Test Machine," NASA CR-135083,

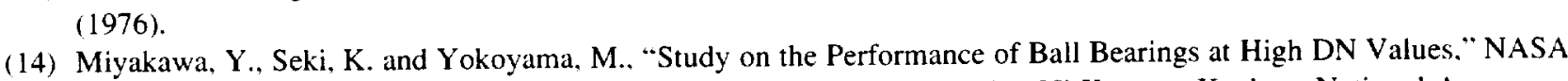
TTF-15017, Translation of Koh DN Chi Ni Okeru Gyokujikuju No Seino Ni Kansuru Kenkyu, National Aerospace Lab., Tokyo, Japan, Report, NAL-TRL-284, (1973).

(15) Hadden, G.B., Kleckner, R.J.. Ragen, M.A. and Sheynin, L., "Manual for Computer Program AT81Y003 SHABERTH. Steady State and Transient Thermal Analysis of a Shaft Bearing System Including Ball, Cylindrical. and Tapered Roller Bearings." NASA CR-165365, (1981).

(16) Zaretsky, E.V., ed.. "STLE Life Factors for Rolling Bearings," STLE. Park Ridge, IL. SP-34, (1992).

(17) Coe, H.H. and Zaretsky, E.V., "Predicted and Experimental Performance of Jet-Lubricated 120-Millimeter-Bore Ball Bearings Operating to 2.5 Million DN," NASA TP-1196, (1978).

(18) Coe, H.H. and Schuller, F.T., "Comparison of Predicted and Experimental Performance of Large-Bore Roller Bearing Operation to 3.0 Million DN,”NASA TP-1599, (1980). 


\begin{tabular}{|c|}
\hline Bearing \\
\hline 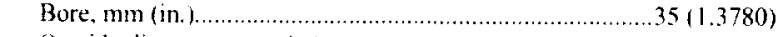 \\
\hline 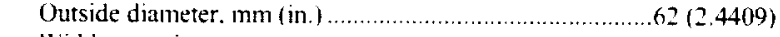 \\
\hline 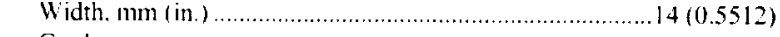 \\
\hline 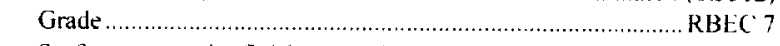 \\
\hline 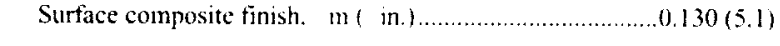 \\
\hline Cage \\
\hline Diametral land clearance, $\mathrm{mm}$ (in.) \\
\hline Outer-land-guided........................ \\
\hline 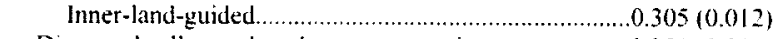 \\
\hline Diametral roller pocket clearance, $\mathrm{mm}$ (in.) ......................356 (0.014) \\
\hline Roller pocket axial clearance. $\mathrm{mm}$ (in.) ........................ $0.178(0.007)$ \\
\hline $\begin{array}{l}\text { Material } \\
\text { plated per AMS } 24120.03 \mathrm{~mm} \\
(0.0012) \text { thick }\end{array}$ \\
\hline Hardness. Rockwell $C$..................................................... 28 to 32 \\
\hline Rollers \\
\hline Number. \\
\hline Size \\
\hline 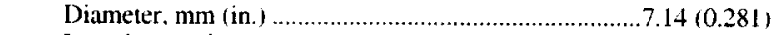 \\
\hline 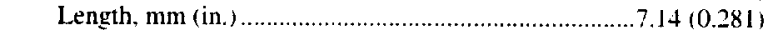 \\
\hline 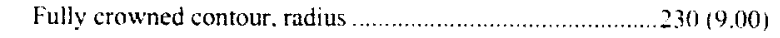 \\
\hline Aerospace crown \\
\hline 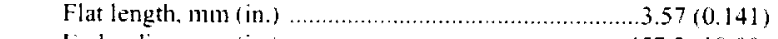 \\
\hline End radius, $\mathrm{mm}$ (in.) ...........................................457.2(18.00) \\
\hline Race \\
\hline Surface finish. micron (micro-inch) ............................... $0.12(4.8)$ \\
\hline $\begin{array}{r}\text { Intemal diametral clearance (IDC). mm (in.) ..................0.05330.0635 } \\
(0.0021 / 0.0025)\end{array}$ \\
\hline STLE life factors (from Ref. 15 ) \\
\hline For material, $\mathrm{a}_{2}$ \\
\hline Processing \\
\hline 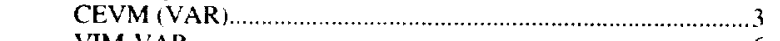 \\
\hline VIM-VAR \\
\hline \\
\hline
\end{tabular}

TABLE 2.-PROPERTIES OF NEOPENTYLPOLYOL (TETRA) ESTER LUBRICANT

\begin{tabular}{|c|}
\hline $\begin{array}{l}\text { Additives } \\
\text { Corrosion and oxidation inhibitors and antiwear and antifoam additives }\end{array}$ \\
\hline Kinematic viscosity. cS, at \\
\hline 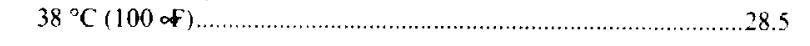 \\
\hline 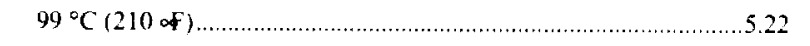 \\
\hline 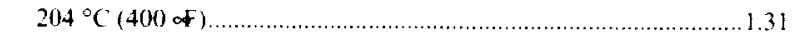 \\
\hline 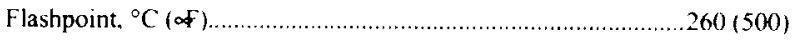 \\
\hline 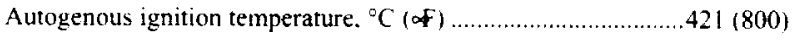 \\
\hline Pour point. ${ }^{\circ} \mathrm{C}$ (of) \\
\hline 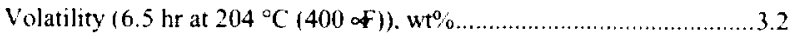 \\
\hline Specific heat at $99{ }^{\circ} \mathrm{C}(210 \circ f), \mathrm{J} / \mathrm{kg}{ }^{\circ} \mathrm{C}(\mathrm{Btu} / \mathrm{lb} \circ \mathrm{\circ f}) \ldots \ldots \ldots \ldots . . .2140(0.493)$ \\
\hline Thermal conductivity at $204^{\circ} \mathrm{C}(400 \propto \mathrm{f})$. \\
\hline $\mathrm{J} / \mathrm{m} \cdot \mathrm{sec}^{\circ}{ }^{\circ} \mathrm{C}(\mathrm{Bru} / \mathrm{hr} \cdot \mathrm{ft} \cdot$ of $) \ldots \ldots \ldots \ldots \ldots \ldots \ldots$ \\
\hline Specific gravity at $99^{\circ} \mathrm{C}(210$ क $)$. \\
\hline Specification .................................. \\
\hline
\end{tabular}




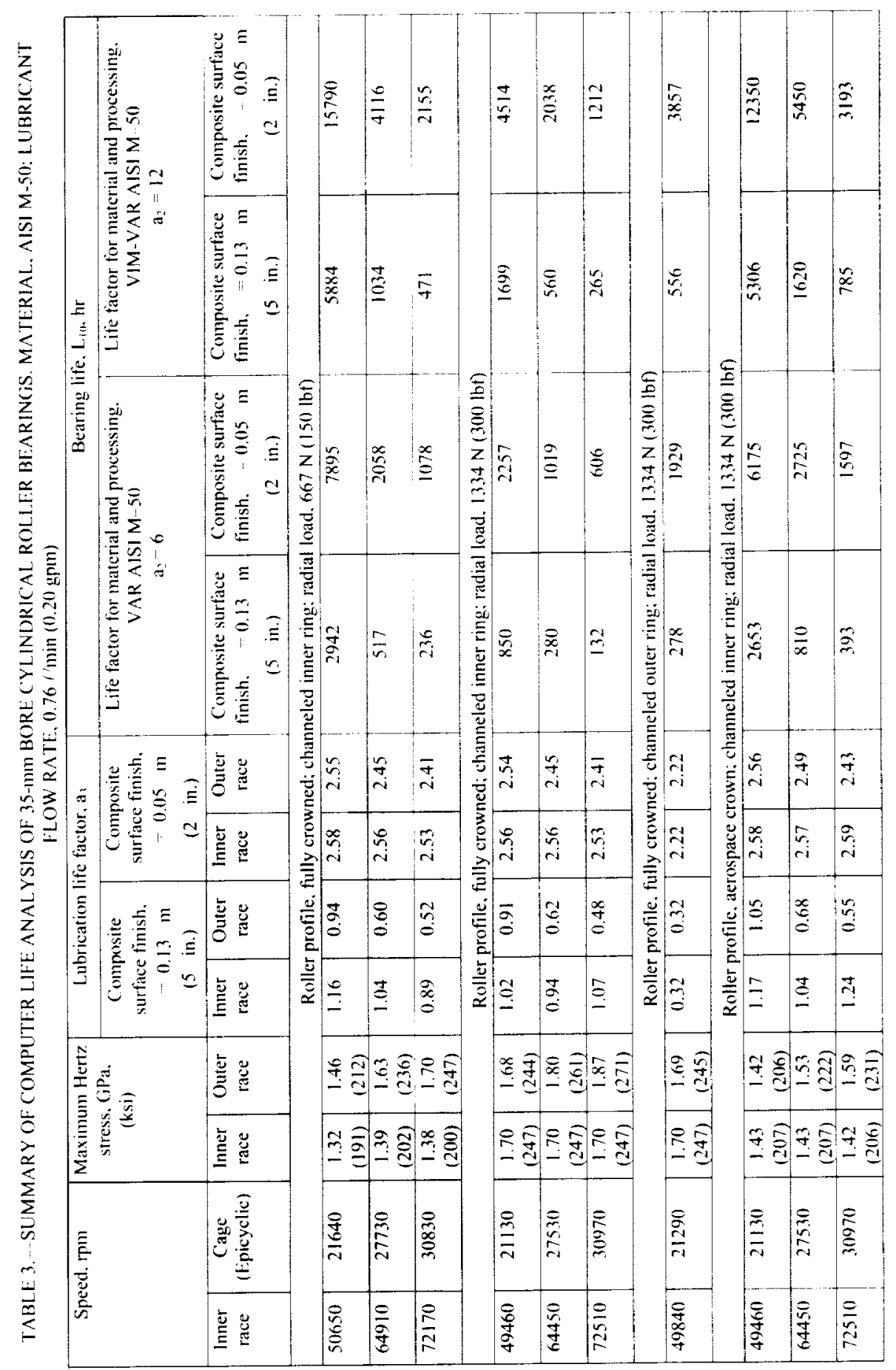




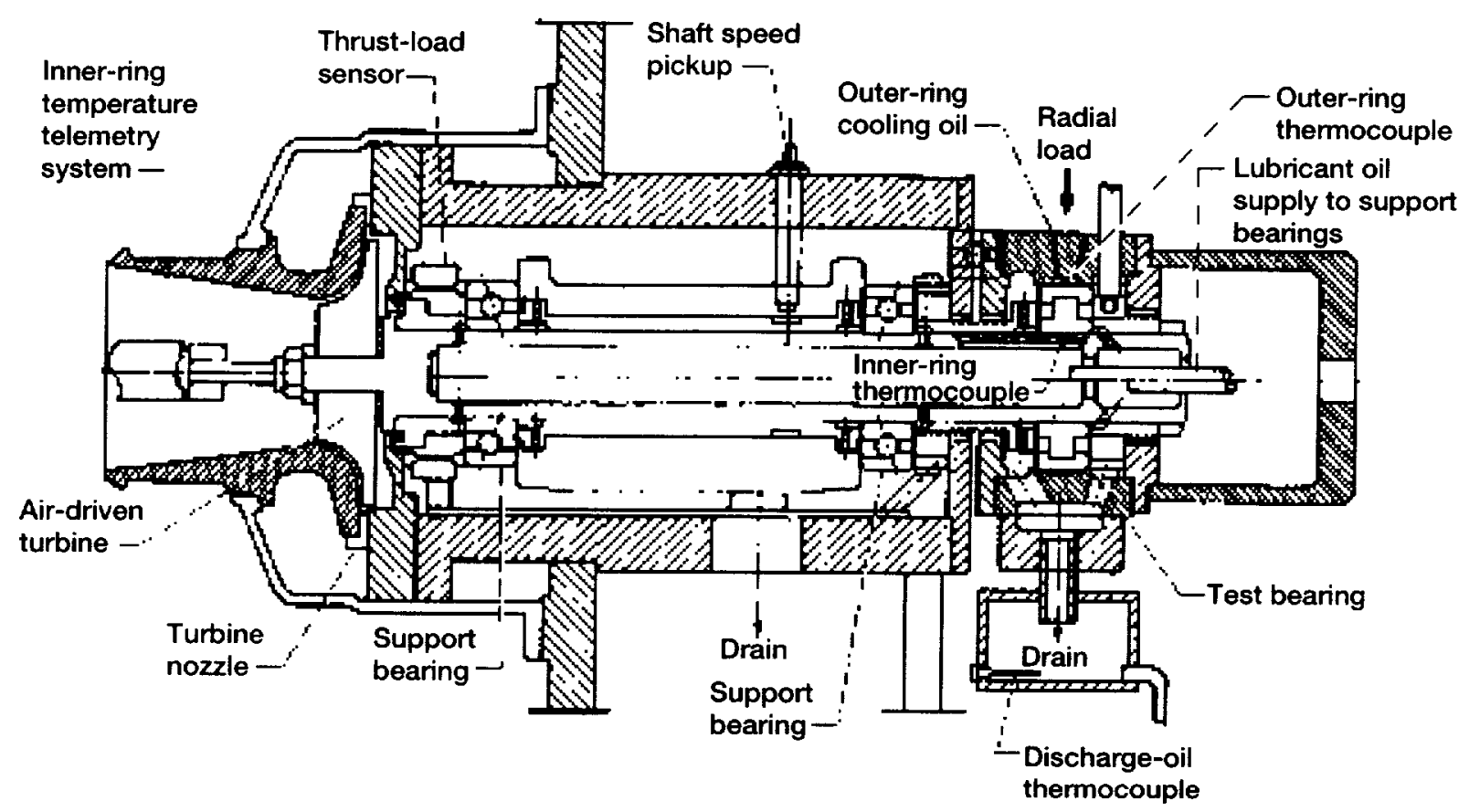

Figure 1.-High-speed, small-bore-bearing tester.
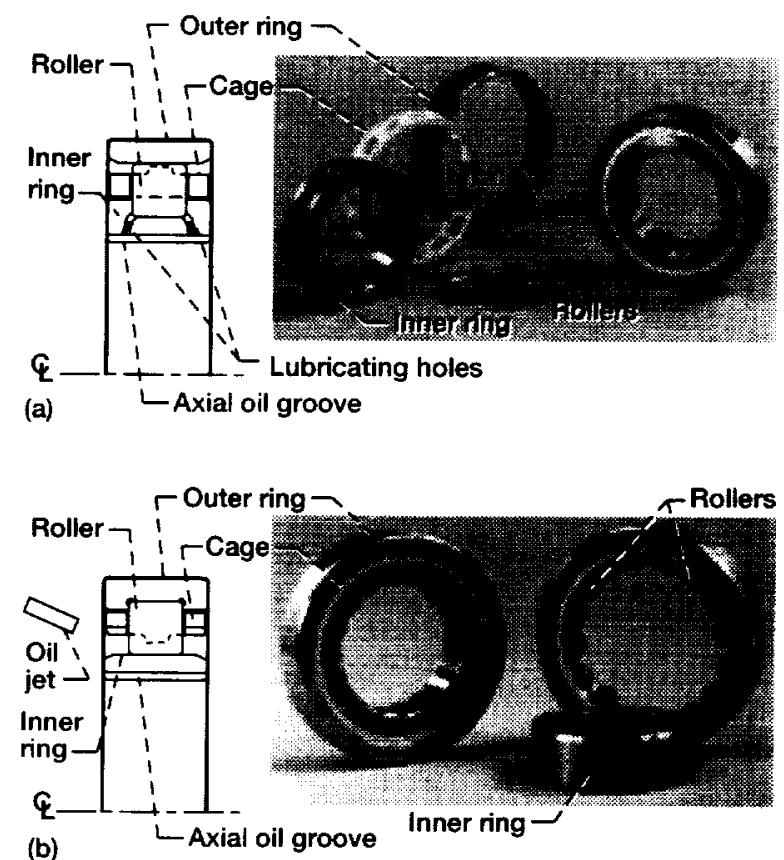

Figure 2.-35-mm-bore cylindrical roller bearing.

(a) Inner-ring channeled, under-ring lubricated and cooled. (b) Outer-ring channeled, under-ring cooled. 


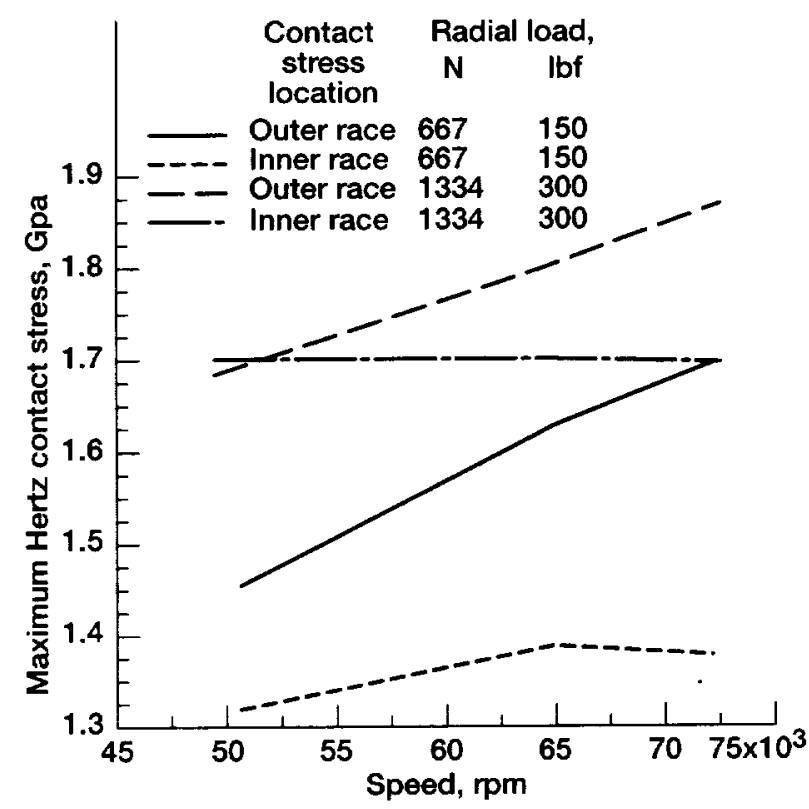

Figure 3.-Effect of Speed on maximum Hertz stress for 35-mm-bore cylindrical roller bearing under radial load.
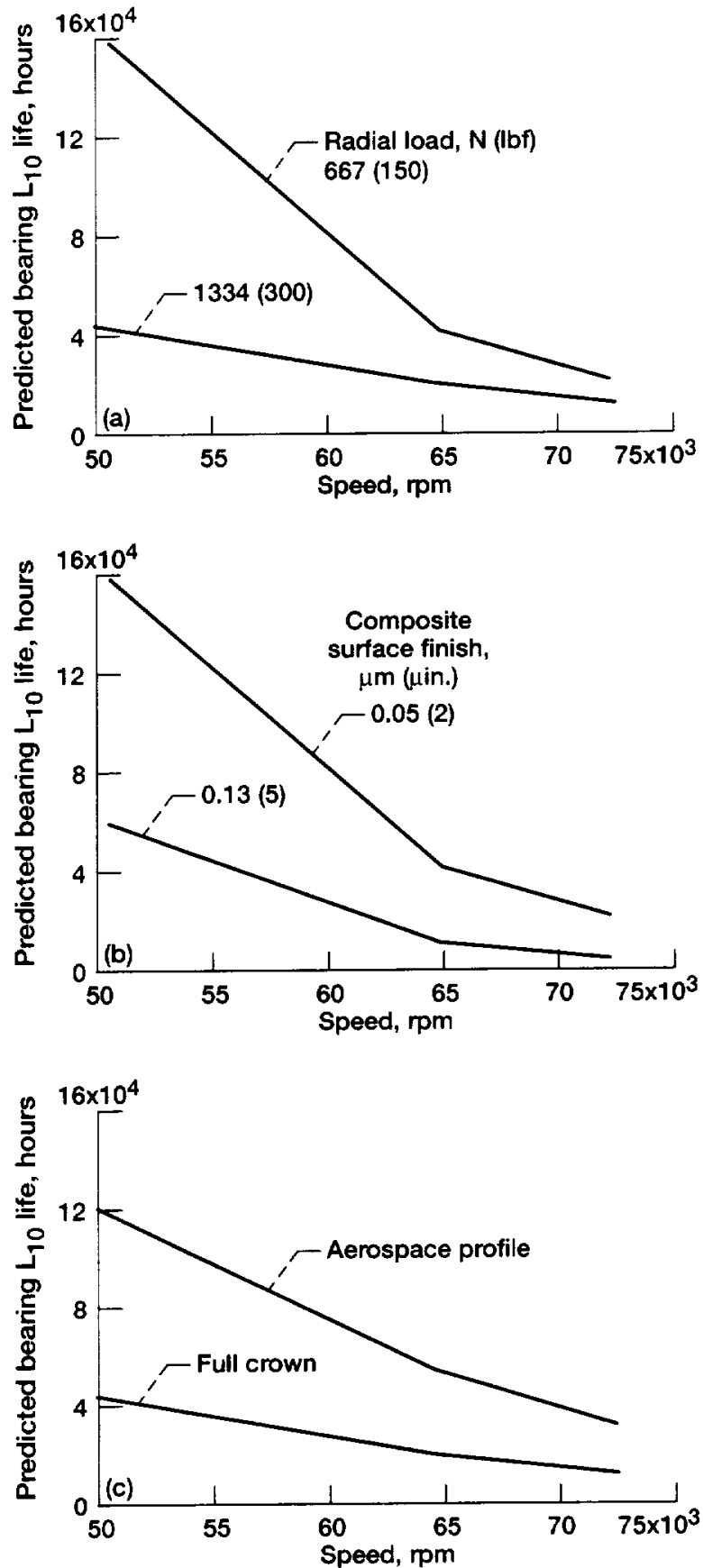

Figure 4.-Predicted bearing $\mathrm{L}_{10}$ life of $35-\mathrm{mm}$-bore cylindrical roller bearing. Material, AISI M-50 steel having channeled inner ring (based on measured ring temperatures without outer-ring cooling) as a function of speed, material processing and surface finish. (a) Effect of load. Composite surface finish, $0.05 \mu \mathrm{m}$ ( $2 \mu \mathrm{in}$.); roller geometry, full crown. (b) Effect of surface finish. Radial load, 667 N (150 lbf); roller geometry, full crown. (c) Effect of roller profile. Composite surface finish, $0.05 \mu \mathrm{m}$ ( $2 \mu \mathrm{in}$.); radial load, 1334 N (300 lbf). 


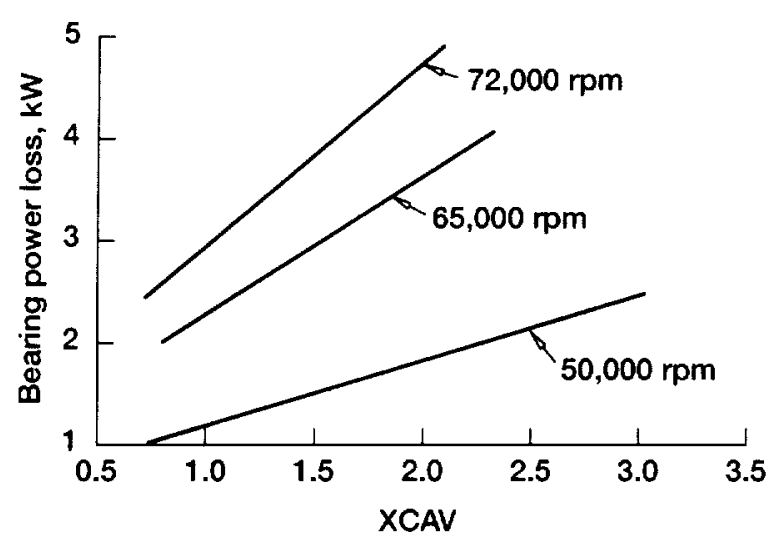

Figure 5.-Effect of lubricant volume percent (XCAV) on bearing power loss calculated by SHABERTH computer program. Bearing type; channeled inner-ring cylindrical roller bearing; lubrication, through inner ring; oil inlet temperature, $121^{\circ} \mathrm{C}\left(250^{\circ} \mathrm{F}\right)$; lubricant, neopentylpolyol (tetra) ester (MIL-L-23699).
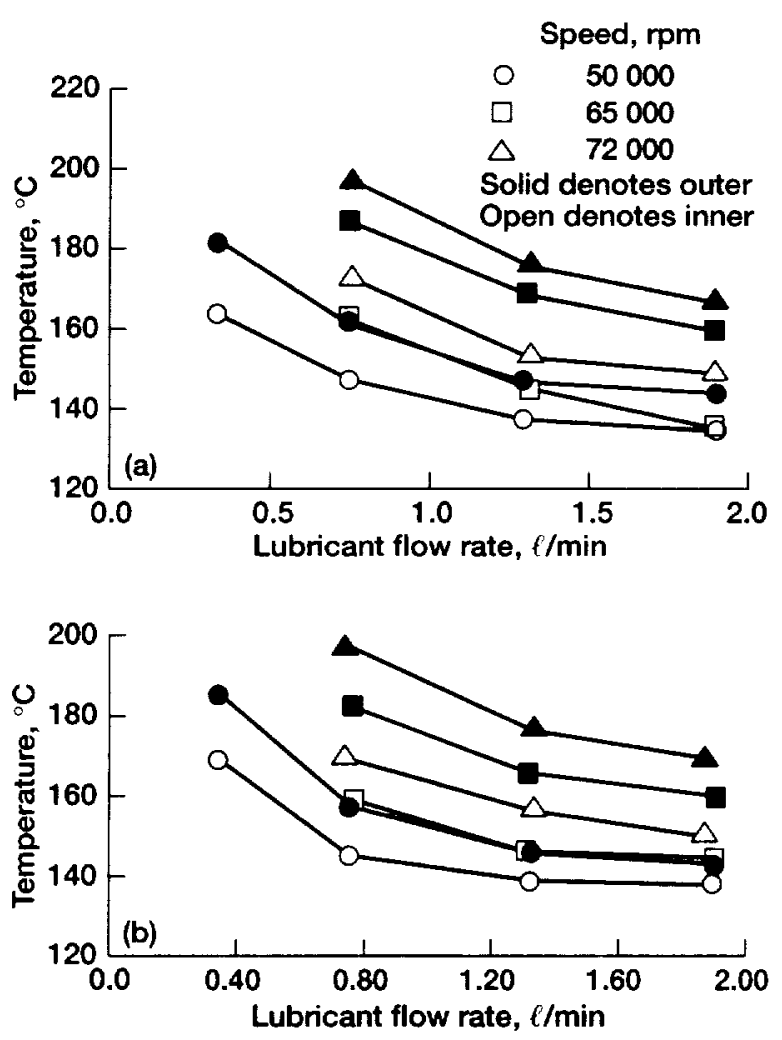

Figure 6.-Effect of lubricant flow rate on measured temperature of 35-mm-bore cylindrical roller bearing with channeled inner ring. Temperatures measured without outer-ring cooling. (a) Radial load, $667 \mathrm{~N}$ (150 lbf). (b) Radial load, 1334 N (300 lbf).
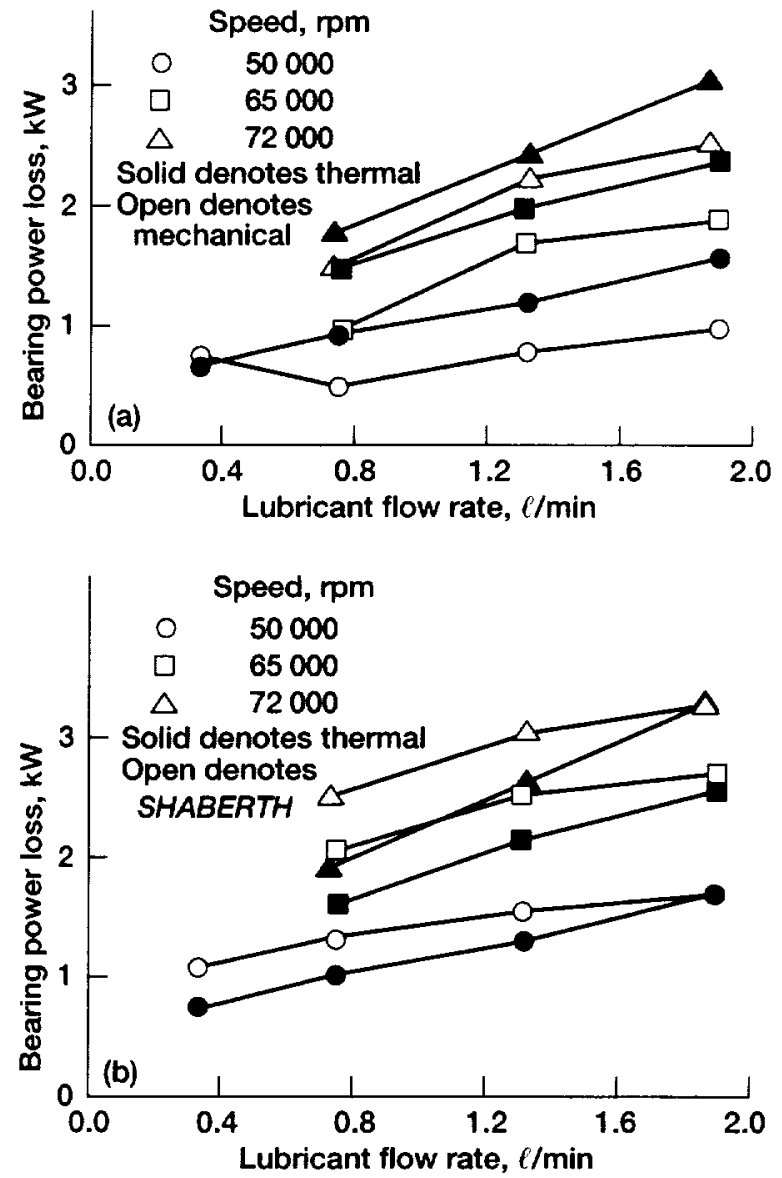

Figure 7.-Effect of lubricant flow rate on measured and predicted power loss of 35-mm-bore cylindrical roller bearing with channeled inner ring. Radial load, $1334 \mathrm{~N}$ (300 lbf). (a) Power determined from thermal data and mechanical test data. (b) Power determined from themal test data and calculated from SHABERTH computer program. 

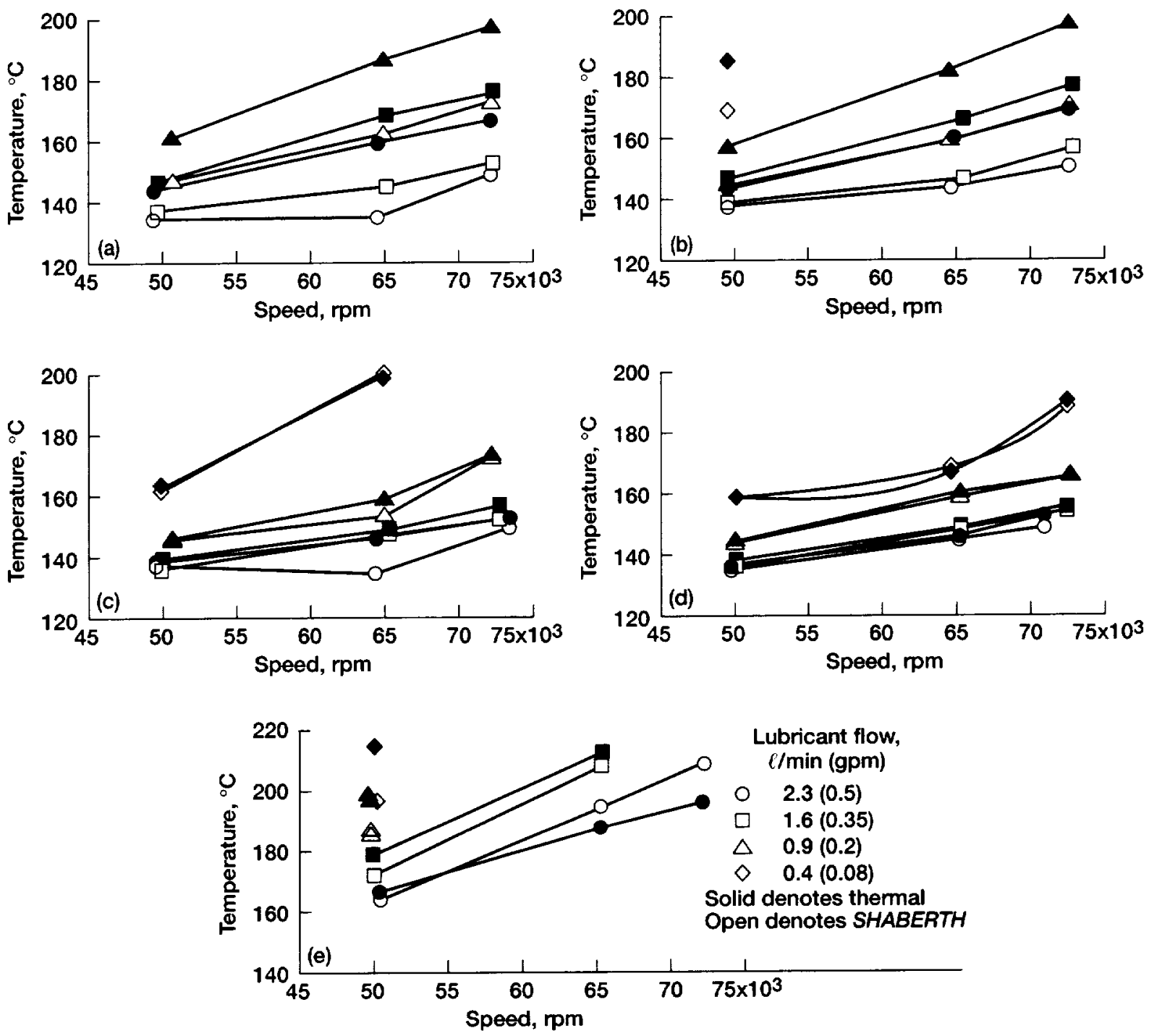

Figure 8.-Measured inner- and outer-ring temperatures as function of speed and oil flow rate for 35-mm-bore cylindrical roller bearing. (a) Channeled inner ring without outer-ring cooling; radial load, $667 \mathrm{~N}$ (150 lbf). (b) Channeled inner ring without outer-ring cooling; radial load, $1334 \mathrm{~N}$ (300 lbf). (c) Channeled inner ring with outer-ring cooling; radial load, $667 \mathrm{~N}$ (150 lbf). (d) Channeled inner ring with outer-ring cooling; radial load, $1334 \mathrm{~N}$ (300 lbf). (e) Channeled outer ring without outer-ring cooling; radial load, $1334 \mathrm{~N}$ (300 lbf). 

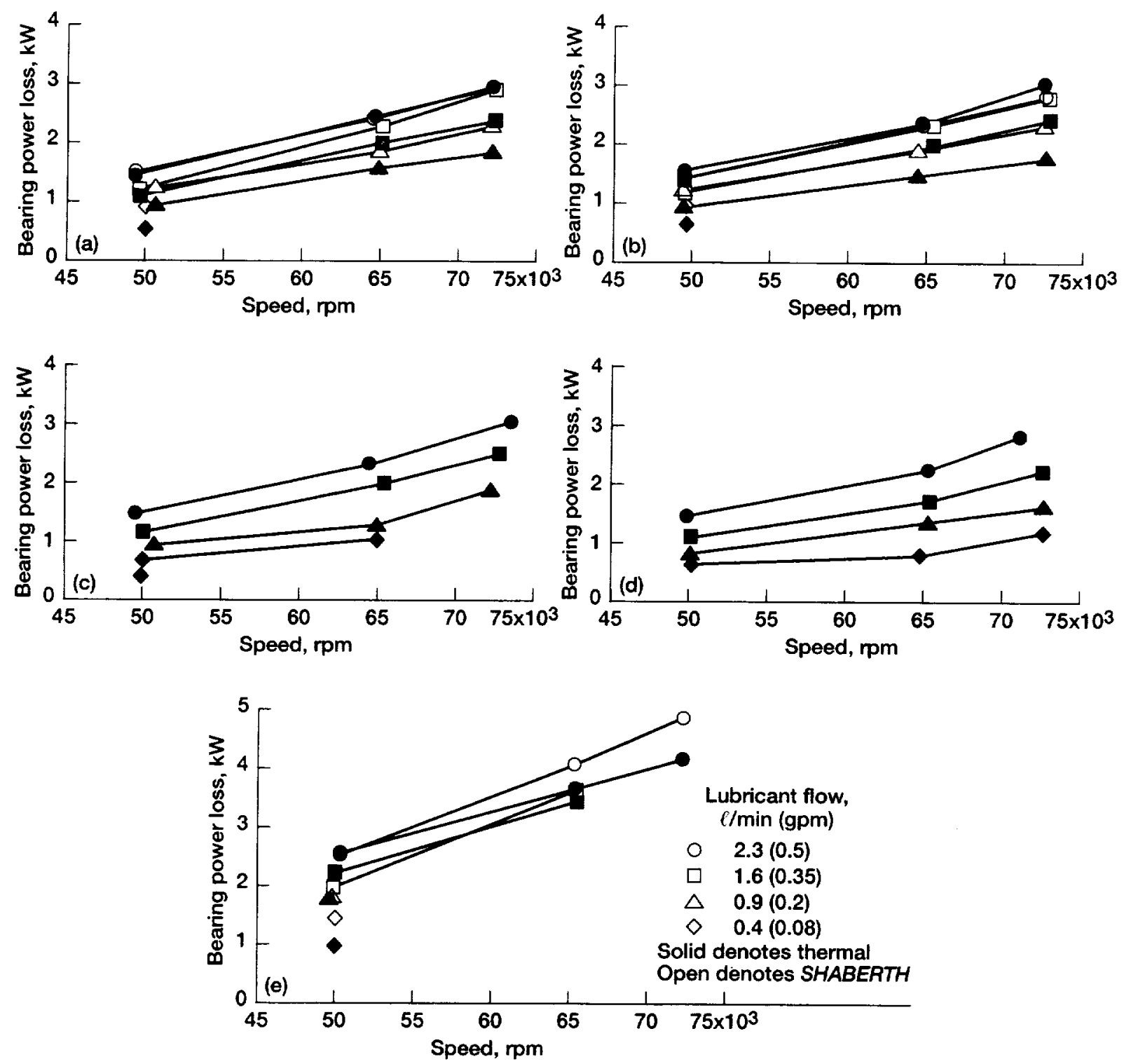

Figure 9.-Effect of speed on measured and predicted power loss of 35-mm-bore cylindrical roller bearing. Power determined from thermal test data and calculated by SHABERTH computer program. (a) Channeled inner ring without outer-ring cooling; radial load, $667 \mathrm{~N}(150 \mathrm{lbf})$. (b) Channeled inner ring without outer-ring cooling; radial load, $1334 \mathrm{~N}$ (300 lbf). (c) Channeled inner ring with outer-ring cooling; radial load, $667 \mathrm{~N}$ (150 lbf). (Test data only.) (d) Channeled inner ring with outer-ring cooling; radial load, $1334 \mathrm{~N}$ (300 lbf). (Test data only.) (e) Channeled outer ring without outer-ring cooling; radial load, $1334 \mathrm{~N}$ (300 lbf). 

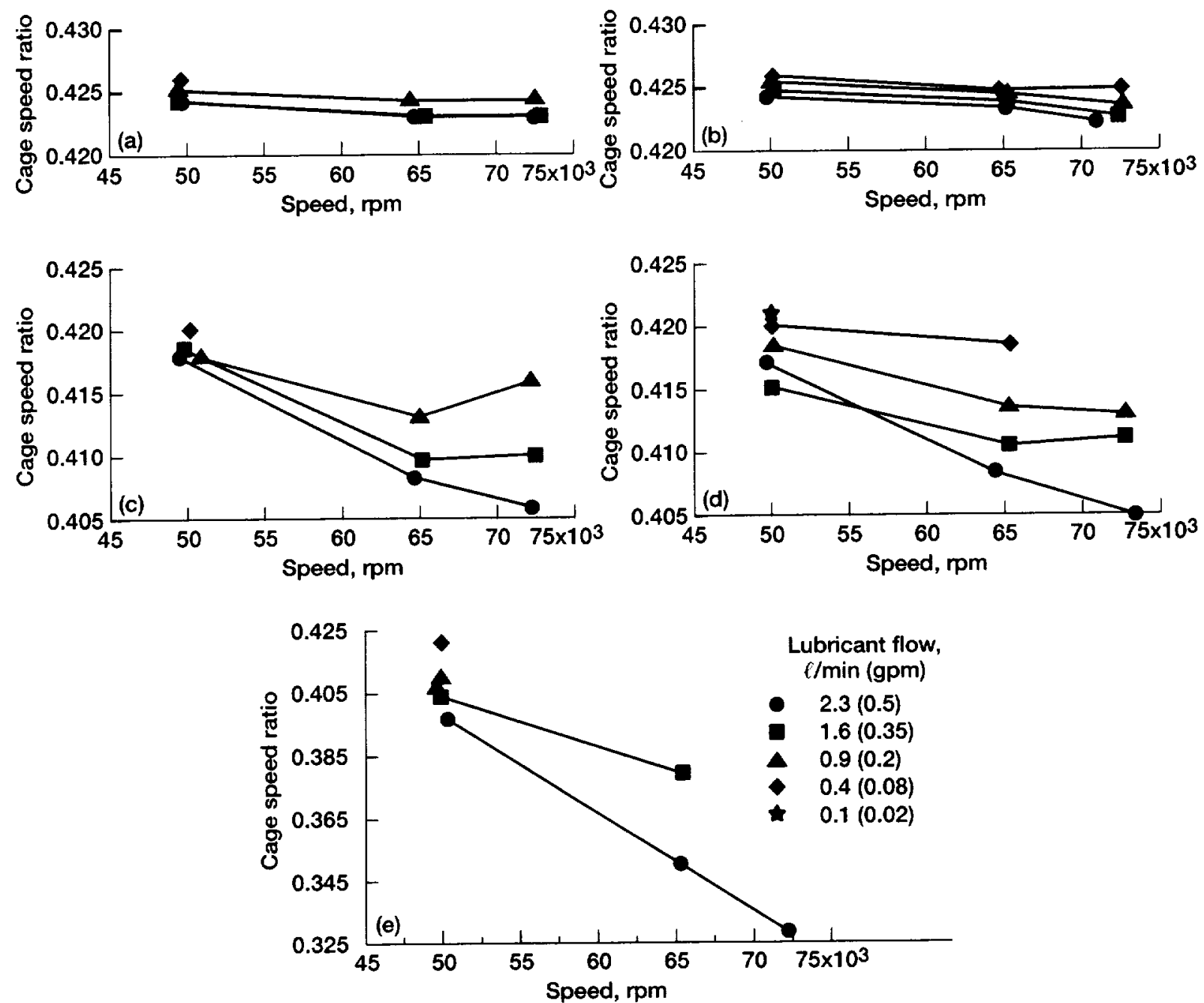

Figure 10.-Measured bearing cage speed ratio for 35- $\mathrm{mm}$-bore cylindrical roller bearing. (a) Channeled inner ring without outer-ring cooling; radial load, $1334 \mathrm{~N}$ (300 lbf). (b) Channeled inner ring with outer-ring cooling; radial load, $1334 \mathrm{~N}$ (300 lbf). (c) Channeled inner ring without outer-ring cooling; radial load, $667 \mathrm{~N}$ (150 lbf). (d) Channeled inner ring with outer-ring cooling; radial load, $667 \mathrm{~N}(150 \mathrm{lbf})$. (e) Channeled outer ring without outer-ring cooling; radial load, $1334 \mathrm{~N}$ (300 lbf). 
Public reporting burden for this collection of information is estimated to average 1 hour per response, including the time for reviewing instructions, searching existing data sources gathering and maintaining the data needed. and completing and reviewing the collection of information. Send comments regarding this burden estimate or any other aspect of this collection of inlormation, including suggestions for reducing this burden. to Washington Headquarters Services. Directorate for Information Operations and Reports, 1215 Davis Highway, Suite 1204, Arlington, VA 22202-4302. and to the Olfice ol Management and Budget. Paperwork Reduction Project (0704-0188), Washington, DC 20503.

\begin{tabular}{|l|l|l|}
\hline 1. AGENCY USE ONLY (Leave blank) & 2. REPORT DATE & 3. REPORT TYPE AND DATES COVERED
\end{tabular}

\begin{tabular}{|l|l|l} 
& August 2000 & Technical Memorandum \\
\hline 4. TITLE AND SUBTITLE & 20
\end{tabular}

4. TITLE AND SUBTITLE 5. FUNDING NUMBEAS

Design and Operating Characteristics of High-Speed, Small-Bore

Cylindrical-Roller Bearings

6. AUTHOR(S)

WU-253-02-98-00

Stanley I. Pinel, Hans R. Signer. and Erwin V. Zaretsky

7. PERFORMING ORgANIZATION NAME(S) AND ADDRESS(ES)

National Aeronautics and Space Administration

John H. Glenn Research Center at Lewis Field

Cleveland, Ohio 44135-3191

8. PERforming organization REPORT NUMBER

E-12060

9. SPONSORING/MONITORING AGENCY NAME(S) AND ADDRESS(ES)

10. SPONSORING/MONITORING

National Aeronautics and Space Administration

Washington, DC 20546-0001 AGENCY REPORT NUMBER

NASA TM-2000-209778

\section{SUPPLEMENTARY NOTES}

Prepared for the 2000 Annual Meeting sponsored by the Society of Tribologists and Lubrication Engineers, Nashville, Tennessee, May 7-1 1, 2000. Stanley I. Pinel, Pinel Engineering, Fullerton, California: Hans R. Signer, Signer Technical Services, Fullerton, California; and Erwin V. Zaretsky, NASA Glenn Research Center. Responsible person, Erwin V. Zaretsky, organization code 5900, (216) 433-3241.

\begin{tabular}{|l|l}
\hline 12a. DISTRIBUTION/AVAILABILITY STATEMENT & 12b. DISTRIBUTION CODE
\end{tabular}

Unclassified - Unlimited

Subject Categories: 37 and 39

Distribution: Nonstandard

This publication is available from the NASA Center for AeroSpace Information. (301) 621-0390.

13. ABSTRACT (Maximum 200 words)

The computer program SHABERTH was used to analyze $35-\mathrm{mm}$-bore cylindrical roller bearings designed and manufactured for high-speed turbomachinery applications. Parametric tests of the bearings were conducted on a high-speed, hightemperature bearing tester and the results were compared with the computer predictions. Bearings with a channeled inner ring were lubricated through the inner ring, while bearings with a channeled outer ring were lubricated with oil jets. Tests were run with and without outer-ring cooling. The predicted bearing life decreased with increasing speed because of increased contact stresses caused by centrifugal load. Lower temperatures, less roller skidding and lower power losses were obtained with channeled inner rings. Power losses calculated by the SHABERTH computer program correlated reasonably well with the test results. The Parker formula for XCAV (used in SHABERTH as a measure of oil volume in the bearing cavity) needed to be adjusted to reflect the prevailing operating conditions. The XCAV formula will need to be further refined to reflect roller bearing lubrication, ring design, cage design, and location of the cage-controlling land.

\section{SUBJECT TERMS}

Rolling-element bearings; Roller bearings: Engineering analysis and computing: Life prediction methods

\begin{tabular}{|c|c|}
\hline $\begin{array}{c}\text { 17. SECURITY CLASSIFICATION } \\
\text { OF REPORT } \\
\text { Unclassified }\end{array}$ & $\begin{array}{c}\text { 18. SECURITY CLASSIFICATION } \\
\text { OF THIS PAGE } \\
\text { Unclassified }\end{array}$ \\
\hline
\end{tabular}

NSN 7540-01-280-5500

19. SECURITY CLASSIFICATION
OF ABSTRACT
Unclassified

Standard Form 298 (Rev. 2-89)

Prescribed by ANSI Std. 239-18 298-102 


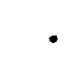




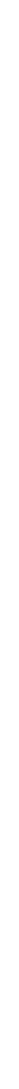

